\title{
Principal Component Analysis in Genetic Resources of Chinese Millet (Setaria italica (L.) Beauv.)
}

\author{
K. Amarnath ${ }^{1 *}$, A.V.S. Durga Prasad ${ }^{1}$ and C.V. Chandra Mohan Reddy ${ }^{2}$ \\ ${ }^{1}$ Department of Genetics \& Plant Breeding, Agricultural College, Mahanandi - 518 502, \\ A.P., India \\ ${ }^{2}$ (Small millets), Regional Agricultural Research Station, Nandyal - 518 501, A.P., India
}

*Corresponding author

\begin{abstract}
A B S T R A C T
\section{Ke y words}

Genetic divergence, Chinese millet genetic resources, Metric traits, Principal component analysis

Article Info

Accepted: 24 September 2018 Available Online: 10 October 2018

\section{Introduction}

Among the Small millets, Chinese millet popularly known as Foxtail millet, German millet, Italian millet, Red Rala millet and Korra (Andhra Pradesh) ranks second in production next to finger millet in our country. According to Vavilov, China is the considered as the centre of origin for this crop. Post green revolution, the cultivation of this small millet is slowly expanding owing to its distinct nutraceutical properties and ability to withstand biotic and abiotic stresses. In terms of area and turnover, this minor millet accounts for $80 \mathrm{k}$ ha. $-900 \mathrm{~kg} \mathrm{ha}^{-1}$ and $51 \mathrm{k}$ ha.
\end{abstract}

Field experiment was conducted in 50 Chinese millet genetic resources to assess the genetic divergence for 12 metric traits through Principal Component Analysis. The ANOVA revealed existence of highly significant variation for all the traits examined. About 69.15 per cent of total variation accrued through Principal component analysis exhibited four Principal components (PC1-29.65\%, PC2-16.94\%, PC3-12.27\% and PC4$10.27 \%)$ retained based on the Scree plot and threshold Eigen value greater than one $(>1)$. The PC1 with prime economical traits viz., days to $50 \%$ flowering, days to maturity, culm branches, thousand grain weight, number of productive tillers / plant and flag leaf blade length accounted for maximum variance $(29.65 \%)$ connoting that these traits be given priority in future Chinese millet breeding programmes.
- $945 \mathrm{~kg} \mathrm{ha}^{-1}$ in India and Andhra Pradesh, respectively (Annual report, 2016-17). Wide gene base in Chinese millet provides ample scope for breeders to exploit through various breeding strategies and generate cultigens with promising traits suited to climate resilient agriculture. Moreover, estimates of genetic relationships can be useful for identification of parents for hybridization, and for reducing the number of accessions needed to maintain a broad range of genetic variability (Bezaweletaw, 2011). Principal component analysis (PCA), a multivariate technique is used to classify the genetic relationships between the traits in multi-trait systems and 
for identifying the patterns of data by reducing the number of dimensions. It also provides an insight into the process contributing differences in yield among genetic resources, a vital aspect in identification and selection of top ranking genetic resources out of diverse germplasm base. PCA results in generation of a 2D / 3D scatter plot of individuals and characters, whose geometrical distances helps in identification of correlated traits and identification of sets of genetically similar individuals (Mohammadi, 2003).

\section{Materials and Methods}

Fifty genetic resources of Chinese millet were raised during kharif, 2017 in a completely randomized block design replicated thrice at Regional Agricultural Research Station, Nandyal, Andhra Pradesh, India. Recommended crop production practices and plant protection measures suggested for this crop were scrupulously followed to raise a healthy crop. Inter-Intra row spacing of $22.5 \mathrm{x}$ $10 \mathrm{~cm}$ was adopted. Twelve metric traits viz., days to 50 per cent flowering, days to maturity, plant height, flag leaf blade length, flag leaf blade width, peduncle length, peduncle exertion, panicle length, culm branches, number of productive tillers / plant, thousand grain weight and grain yield / plant were recorded on five randomly selected plants in each entry per replication. The data was subjected to statistical analysis for PCA using the software WINDOWSTA of 9.2 version as per the procedure outlined by Rao (1952).

\section{Results and Discussion}

The analysis of variance for 12 metric traits in 50 Chinese millet genetic resources (Table 1) revealed existence of ample genetic variation in the material, an important pre-requisite that paved way for further diversity analysis. The canonical root values, per cent of variation and cumulative variation elucidated for 50 Chinese millet genetic resources were presented in Table 2. Through principal component analysis (PCA), the number of variables was reduced to linear functions viz., 'canonical vectors' that accrued for much of the variation exhibited by traits studied. The mean values of canonical variates for three roots X, Y and Z. Two dimensional (2D) and three dimensional (3D) illustrations (Fig. 1 and 2) were constructed by plotting the mean values of vectors. The amount of contribution of various traits in canonical vectors to the total divergence is known. PCA identified four PCs that accounted for 69.15 per cent of total divergence (Table 3). The first and second roots contributed 29.65 and 16.94 per cent variabilities respectively to total variability. The remaining two PCs viz., third and fourth showed variabilities of 12.27 and $10.27 \mathrm{per}$ cent respectively towards the total variability. These four PCs were retained (Fig. 3) based on the Scree plot and threshold eigen value greater than one $(>1)$.

In the vector $Z_{1}$, traits contributing towards total divergence positively were 1000 grain weight $(0.26)$, number of productive tillers / plant (0.23), culm branches (0.30), flag leaf blade length (0.22), plant height (0.25), days to $50 \%$ flowering (0.47) and days to maturity (0.46), For the vector $Z_{2}$, days to $50 \%$ flowering (0.07) and culm branches (0.08) contributed positively to the genetic diversity. In the vector $\mathrm{Z}_{3}$, the traits viz., days to $50 \%$ flowering (0.09), peduncle length (0.30), peduncle exertion (0.45), flag leaf blade width (0.04) and culm branches (0.06) had contributed positively to diversity. Flag leaf blade length (0.29) and grain yield / plant (0.29) together contributed maximum to the diversity in vector $Z_{4}$ followed by days to maturity (0.28), days to $50 \%$ flowering (0.27), peduncle exertion (0.12), plant height (0.09), peduncle length (0.07) and flag leaf blade width (0.02) (Table 4). 
Table.1 ANOVA for grain yield and yield attributes in 50 Chinese millet genetic resources

\begin{tabular}{|c|c|c|c|c|}
\hline \multirow[t]{2}{*}{ S. No. } & \multirow[t]{2}{*}{ Characters } & \multicolumn{3}{|c|}{ Mean squares } \\
\hline & & $\begin{array}{l}\text { Replications } \\
\text { (df:2) }\end{array}$ & $\begin{array}{c}\text { Genotypes } \\
\text { (df:49) }\end{array}$ & $\begin{array}{c}\text { Error } \\
\text { (df:98) }\end{array}$ \\
\hline 1. & Days to $50 \%$ flowering & 3.02 & $35.96 * *$ & 2.37 \\
\hline 2. & Days to maturity & 4.53 & $37.07 * *$ & 3.09 \\
\hline 3. & Plant height & 104.27 & $275.89 * *$ & 69.31 \\
\hline 4. & Peduncle length & 11.61 & $33.63 * *$ & 4.83 \\
\hline 5. & Peduncle exertion & 4.61 & $24.15 * *$ & 6.15 \\
\hline 6. & Panicle length & 5.30 & $15.09 * *$ & 4.97 \\
\hline 7. & Flag leaf blade length & 21.33 & $23.88 * *$ & 10.30 \\
\hline 8. & Flag leaf blade width & 0.049 & $0.056 * *$ & 0.019 \\
\hline 9. & Culm branches & 0.002 & $2.39 * *$ & 0.06 \\
\hline 10. & Number of productive tillers / plant & 0.28 & $0.74 * *$ & 0.12 \\
\hline 11. & 1000 grain weight & 0.013 & $0.13 * *$ & 0.00 \\
\hline 12 & Grain yield / plant & 0.60 & $1.60 * *$ & 0.21 \\
\hline
\end{tabular}

** $1 \%$ level of Significance

Table.2 Canonical root values, per cent of variation and cumulative variation explained for 50 Chinese millet genetic resources

\begin{tabular}{|c|c|c|c|}
\hline $\begin{array}{c}\text { Canonical } \\
\text { root }\end{array}$ & $\begin{array}{c}\text { Value of canonical } \\
\text { root }\end{array}$ & $\begin{array}{c}\text { percent of variation } \\
\text { accounted for }\end{array}$ & $\begin{array}{c}\text { Cumulative total } \\
\text { variation accounted for }\end{array}$ \\
\hline$Z_{1}$ & 3.55 & 29.65 & 29.65 \\
\hline$Z_{2}$ & 2.03 & 16.94 & 46.59 \\
\hline$Z_{3}$ & 1.47 & 12.27 & 58.87 \\
\hline$Z_{4}$ & 1.23 & 10.27 & 69.15 \\
\hline
\end{tabular}

Table.3 Canonical vectors for 12 characters in 50 Chinese millet genetic resources

\begin{tabular}{|c|l|c|c|c|c|}
\hline S. No & \multicolumn{1}{|c|}{ Character } & $\mathbf{Z}_{\mathbf{1}}$ & $\mathbf{Z}_{\mathbf{2}}$ & $\mathbf{Z}_{\mathbf{3}}$ & $\mathbf{Z}_{\mathbf{4}}$ \\
\hline 1. & Days to 50\% flowering & 0.47 & 0.07 & 0.09 & 0.27 \\
\hline 2. & Days to maturity & 0.46 & -0.01 & -0.01 & 0.28 \\
\hline 3. & Plant height & 0.26 & -0.46 & -0.03 & 0.09 \\
\hline 4. & Peduncle length & -0.02 & -0.61 & 0.30 & 0.07 \\
\hline 5. & Peduncle width & -0.22 & -0.28 & 0.45 & 0.12 \\
\hline 6. & Panicle length & -0.19 & -0.16 & -0.49 & -0.30 \\
\hline 7. & Flag leaf blade length & 0.22 & -0.19 & -0.36 & 0.29 \\
\hline 8. & Flag leaf blade width & -0.36 & -0.28 & 0.04 & 0.02 \\
\hline 9. & Culm branches & 0.30 & 0.08 & 0.06 & -0.34 \\
\hline 10. & No. of productive tillers / plant & 0.23 & -0.13 & 0.00 & -0.60 \\
\hline 11. & 1000 grain weight & 0.26 & -0.38 & -0.16 & -0.29 \\
\hline 12. & Grain yield / plant & -0.18 & -0.16 & -0.55 & 0.29 \\
\hline & Eigen Value (Root) & 3.56 & 2.03 & 1.47 & 1.23 \\
\hline & Expression of /centage variance & 29.65 & 16.94 & 12.27 & 10.27 \\
\hline & Expression of cumulative variance & 29.65 & 46.60 & 58.87 & 69.15 \\
\hline
\end{tabular}


Table.4 Mean values of canonical vectors for 50 Chinese millet genetic resources

\begin{tabular}{|c|c|c|c|c|}
\hline S. No. & Genotype & X Vector & Y Vector & Z Vector \\
\hline 1. & SiA-3347 & 38.374 & -14.128 & 3.615 \\
\hline 2. & SiA-3340 & 38.982 & -15.310 & 4.548 \\
\hline 3. & $\mathrm{SiA}-3355$ & 35.068 & -17.795 & 2.966 \\
\hline 4. & SiA-3382 & 35.774 & -16.441 & 3.641 \\
\hline 5. & SiA-3085 & 35.383 & -14.389 & 2.304 \\
\hline 6. & SiA-3383 & 35.543 & -15.908 & 1.593 \\
\hline 7. & SiA-3398 & 38.320 & -17.800 & 3.042 \\
\hline 8. & $\mathrm{SiA}-3327$ & 33.638 & -17.171 & 3.185 \\
\hline 9. & $\mathrm{SiA}-3407$ & 36.585 & -16.922 & 2.462 \\
\hline 10. & SiA-3376 & 36.337 & -17.026 & 3.859 \\
\hline 11. & $\mathrm{SiA}-3403$ & 36.383 & -16.804 & 3.190 \\
\hline 12. & SiA-3222 & 25.337 & -15.157 & 2.107 \\
\hline 13. & SiA-3318 & 33.574 & -14.772 & 3.804 \\
\hline 14. & SiA-3381 & 32.675 & -18.136 & 2.381 \\
\hline 15. & SiA-3377 & 35.184 & -14.051 & 2.966 \\
\hline 16. & KDR & 34.492 & -15.806 & 2.671 \\
\hline 17. & SiA-3447 & 37.012 & -15.093 & 2.843 \\
\hline 18. & SiA-3399 & 36.752 & -15.522 & 2.885 \\
\hline 19. & SiA-3395 & 36.224 & -16.324 & 2.361 \\
\hline 20. & Narasimharaya & 35.830 & -16.761 & 1.956 \\
\hline 21. & SiA-3335 & 34.169 & -16.162 & 1.240 \\
\hline 22. & Prasad & 35.436 & -16.195 & 3.991 \\
\hline 23. & SiA-3386 & 35.083 & -17.501 & 2.181 \\
\hline 24. & SiA-3363 & 35.765 & -18.063 & 4.018 \\
\hline 25. & SiA-3354 & 33.891 & -16.661 & 2.782 \\
\hline 26. & SiA-3375 & 34.579 & -16.530 & 4.088 \\
\hline 27 & SiA-3333 & 35.101 & -16.376 & 2.763 \\
\hline 28 & SiA-3369 & 37.262 & -13.026 & 3.383 \\
\hline 29 & SiA-3378 & 35.305 & -18.832 & 3.203 \\
\hline 30 & SiA-3328 & 36.604 & -14.473 & 3.318 \\
\hline 31 & SiA-3346 & 36.666 & -16.980 & 1.408 \\
\hline 32 & SiA-3392 & 36.588 & -18.226 & 2.367 \\
\hline 33 & SiA-3156 & 35.475 & -16.484 & 0.936 \\
\hline 34 & Suryanandi & 34.984 & -16.844 & 3.297 \\
\hline 35 & ISC-379 & 35.390 & -15.948 & 4.040 \\
\hline 36 & SiA-3397 & 38.245 & -17.332 & 3.609 \\
\hline 37 & SiA-3390 & 36.007 & -17.747 & 3.038 \\
\hline 38 & SiA-3393 & 34.261 & -13.040 & 4.299 \\
\hline 39 & SiA-3396 & 37.737 & -15.525 & 3.466 \\
\hline 40 & SiA-3364 & 35.142 & -17.973 & 3.327 \\
\hline 41 & $\mathrm{SiA}-3405$ & 35.940 & -15.525 & 5.053 \\
\hline 42 & SiA-3322 & 32.858 & -17.280 & 5.295 \\
\hline 43 & SiA-3367 & 36.024 & -15.247 & 3.188 \\
\hline 44 & SiA-3394 & 33.545 & -15.247 & 2.738 \\
\hline 45 & SiA-3384 & 38.991 & -16.041 & 3.336 \\
\hline 46 & $\mathrm{SiA}-3400$ & 37.291 & -16.986 & 3.118 \\
\hline 47 & $\mathrm{SiA}-3404$ & 36.799 & -17.077 & 1.852 \\
\hline 48 & SiA-3401 & 36.401 & -13.953 & 2.765 \\
\hline 49 & Sri lakshmi & 36.420 & -16.354 & 1.890 \\
\hline 50 & SiA-3389 & 36.532 & -15.295 & 3.553 \\
\hline
\end{tabular}


Fig.1 Two dimensional (2D) plot of canonical analysis

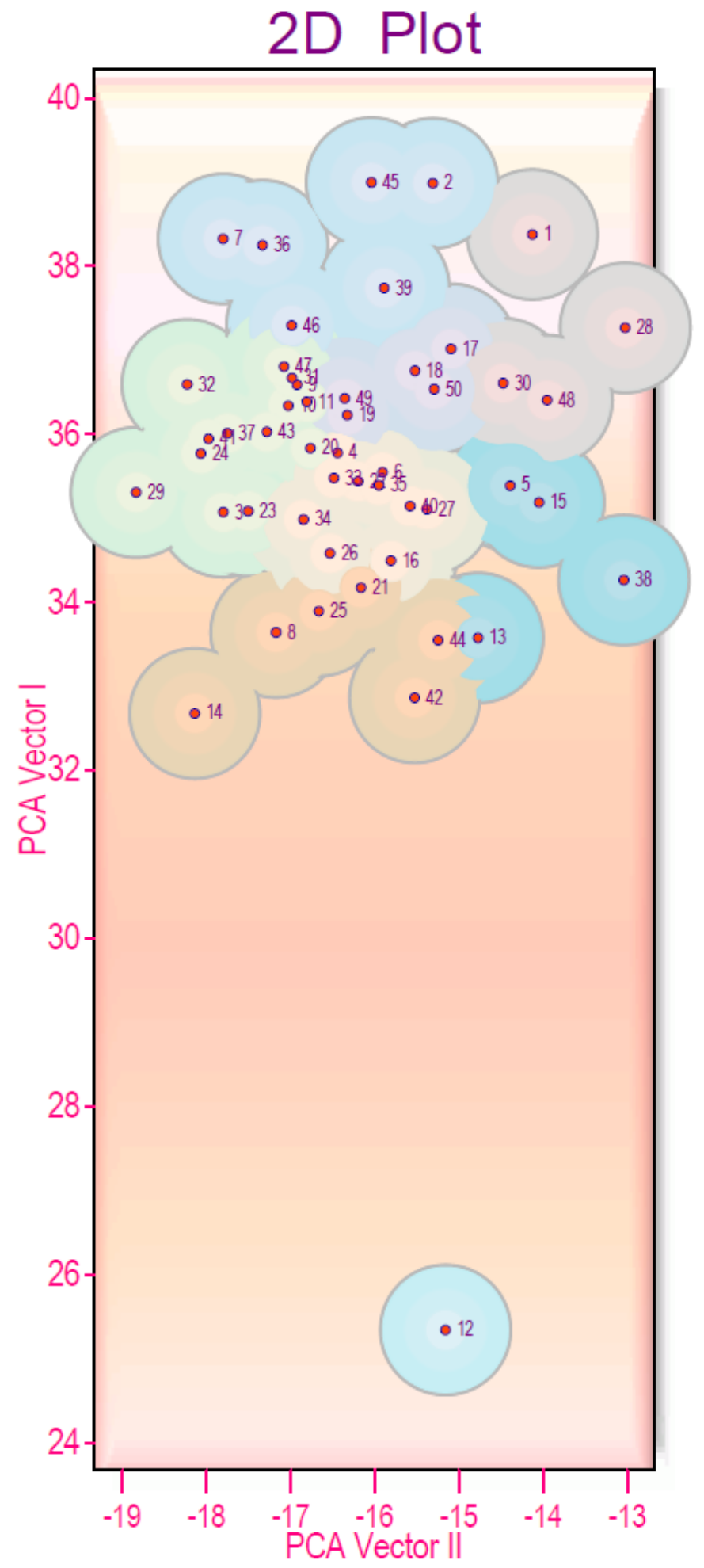


Fig.2 Three dimensional (3D) plot of principal component analysis

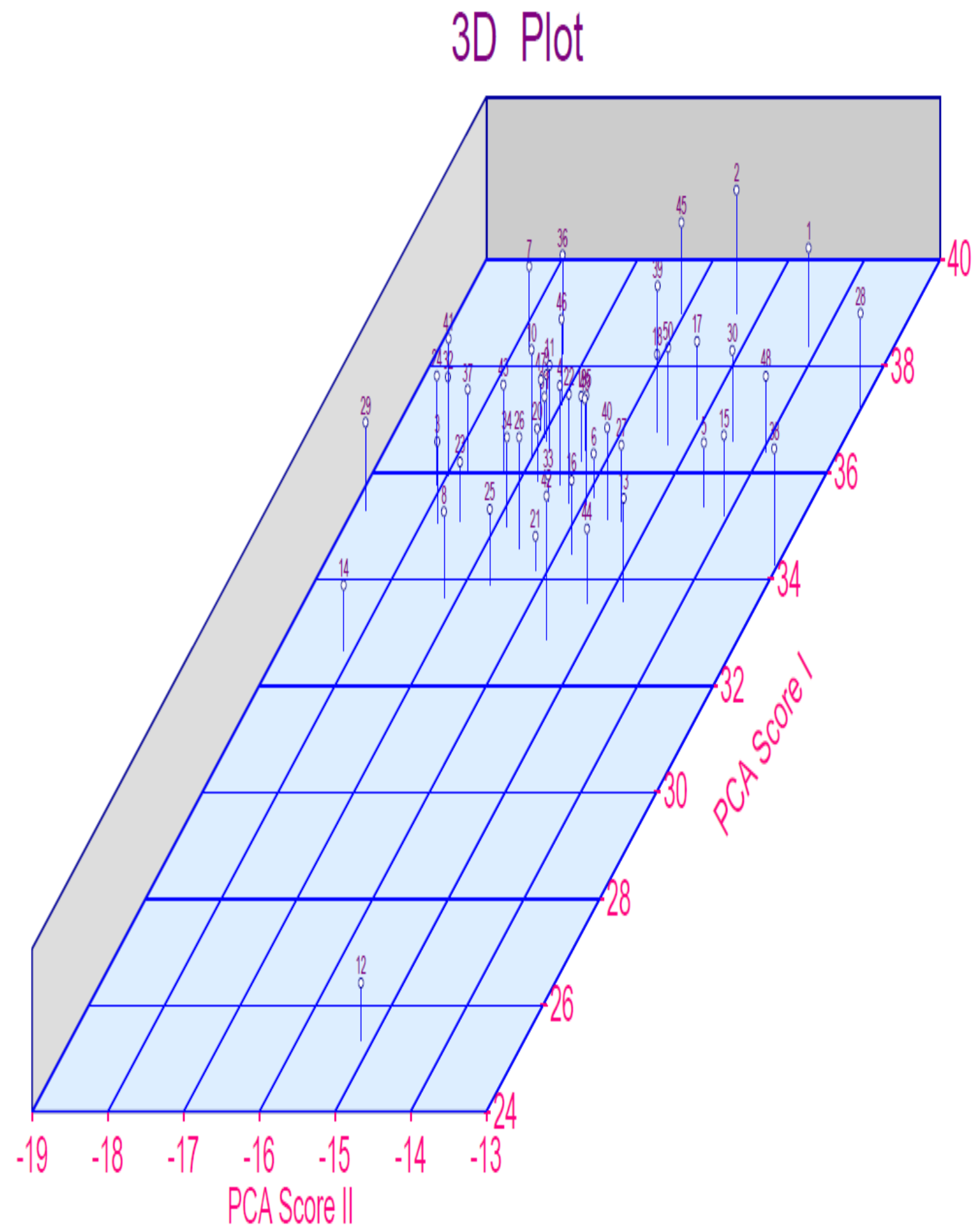


Fig.3 Scree plot showing the Eigen value variation for 12 quantitative traits in 50 Chinese millet genetic resources

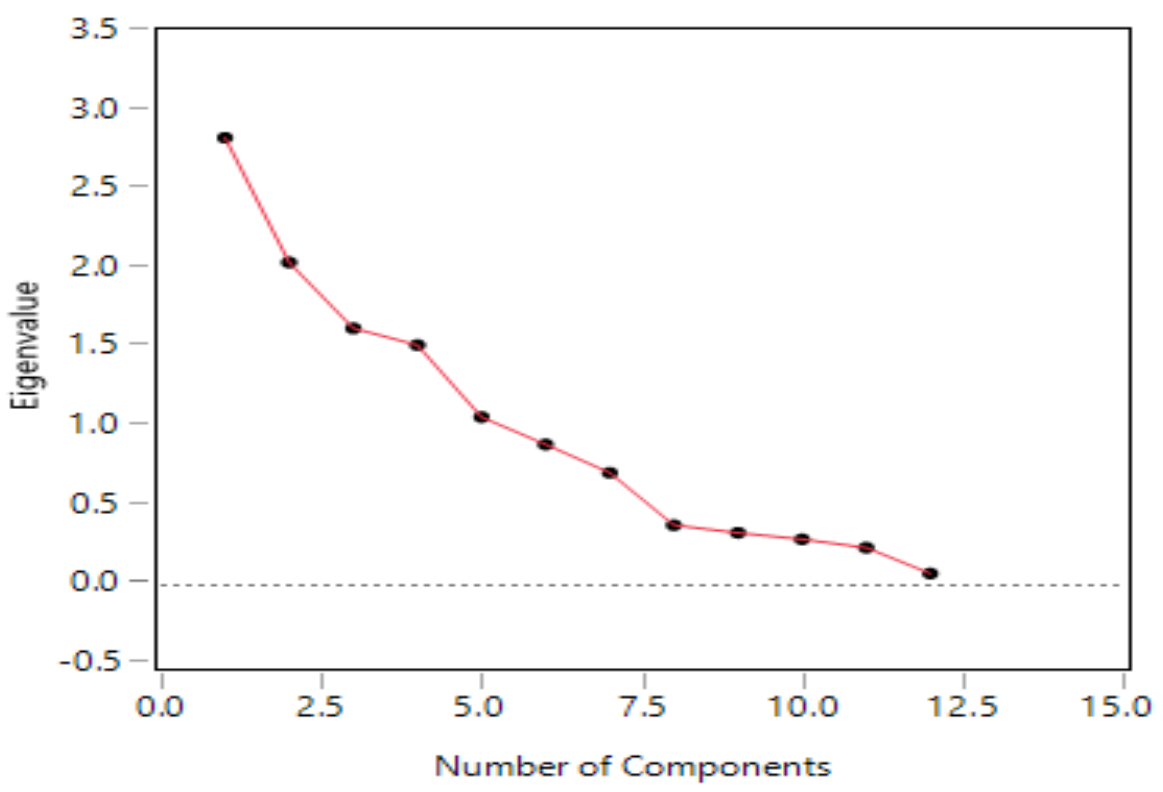

In a nut shell, the PCA results of the present study revealed that four PCs retained based on the Scree plot and threshold Eigen value greater than one $(>1)$ contributed much $(69.15$ per cent) of total genetic divergence.

\section{Acknowledgement}

The authors are highly thankful to Acharya N.G. Ranga Agricultural University, Guntur, Andhra Pradesh, India for providing Chinese millet genetic resources and financial assistance to embellish this study.

\section{References}

Annual report, AICRP on Small Millets. 2016-17. Directorate of Economics and Statistics, Hyderabad-500 004.
Bezaweletaw, K., Sripichitt, P., Wongyai, W and Hongtrakul, V. 2006. Genetic variation, heritability and path-analysis in Ethiopian finger millet (Eleusine coracana (L.) Gaertn) landraces. Kasetsart Journal of Natural Sciences. 40: 322-334.

Mohammadi, SA. 2003. Analysis of genetic diversity in crop plants salient statistical tools and considerations. Crop science. 3 (4): 1235.

Rao, C.R.V. 1952. Advanced statistical methods in biometrical research. John Wiley and Sons Inc., New York, pp. 236- 272.

\section{How to cite this article:}

Amarnath, K., A.V.S. Durga Prasad and Chandra Mohan Reddy, C.V. 2018. Principal Component Analysis in Genetic Resources of Chinese Millet (Setaria italica (L.) Beauv.). Int.J.Curr.Microbiol.App.Sci. 7(10): 3387-3393. doi: https://doi.org/10.20546/ijcmas.2018.710.392 